\title{
A EDUCAÇÃO SOB O SIGNO DA BIOPOLITICA: DA RESISTÊNCIA ÀS FORMAS DE CONTROLE À AUTOCONSTITUIÇÃO DE NÓS MESMOS
}

\author{
Carmelita Brito de Freitas Felício \\ Universidade Federal de Goiás, Goiânia, Goiás, Brasil
}

\begin{abstract}
Resumo: A proposta do ensaio é pensar o devir-educação e suas virtuais relações com a biopolítica. Partimos da hipótese, segundo a qual, as tecnologias de saber-poder e os dispositivos de controle e normalização, não podem funcionar sem um vetor pedagógico. Por isso mesmo, se a biopolítica investe nos corpos para torná-los objetos de controle político, manipulação cultural e instrumentalização econômica, tratar-se-ia de nos opor a esses investimentos e invocar as forças de resistência alojadas nos próprios indivíduos. Para Foucault, o sentido ético da urgente tarefa de constituir uma ontologia histórica da atualidade passa, também, pela indagação do que estamos fazendo de nós mesmos. Ora, se na formação de si está implicada a tarefa de educar contra e para além de seu tempo, levemos então a sério o alerta de Nietzsche com o qual Foucault, certamente, concordaria: os educadores devem começar por se educar a si próprios. "E é para esses que eu escrevo". Palavras-Chave: Biopolítica. Educação. Resistência. Formação de si.
\end{abstract}

\section{INTRODUÇÃO}

Este ensaio é parte de nossa pesquisa cujo foco é a problematização das condições históricas que tornaram possível o nascimento da biopolítica na ordem do saber-poder ocidental, para se chegar às implicações deste acontecimento no campo da educação. As orientações metodológicas 
fundamentais vêm do trabalho filosófico de Michel Foucault, mas interessanos, também, verificar a recepção das ideias do filósofo no trabalho de Gilles Deleuze, como também as redefinições e novas interpretações que os leitores contemporâneos de Foucault vêm propondo acerca do acontecimento educação sob o signo da biopolítica. Assim, os rumos da pesquisa estão ancorados no acesso a essas fontes e na nossa capacidade de leitura e interpretação dos textos. Vimos recorrendo ao procedimento filosófico que conjuga a "análise conceitual" com a análise histórica, para retraçar o caminho do conceito de biopolítica até as experiências históricas concretas e geralmente políticas que lhe deram origem. Outros conceitos permeiam a análise, como é o caso dos conceitos de poder, vida e formas de subjetivação. Assim procedendo, podemos avaliar até que ponto esses conceitos se encontram afastados de suas origens, mapeando-os através do tempo e procurando demarcar pontos de confusão linguística e conceitual. Interessa-nos de perto rastrear a via da genealogia dos poderes, por meio da qual Foucault articula a constituição das ciências biológicas, a partir do século XIX, com outros campos de saber e de práticas, especialmente as pedagógicas. Interessa-nos, sobretudo, pesquisar o pensamento tardio de Foucault, acerca das formas ativas de subjetivação, investigando as condições de possibilidade de se realizar experiências no campo das práticas educativas, com o objetivo de traçar alternativas às formas de vida instituídas e experimentar outras formas possíveis de construção de novas subjetividades, por meio de um trabalho pedagógico comprometido com a "formação de si" e interessado na constituição de um sujeito ético da ação. Aqui a ética "tem como eixo outro elemento que a constitui - a relação dos indivíduos consigo mesmos a partir de uma arte da vida, o cuidado de si" (PORTOCARRERO, 2008, p. 424).

Outro procedimento que vimos adotando se baseia em uma orientação interdisciplinar, para possibilitar o diálogo com pesquisadores das áreas de filosofia política e filosofia da educação, que vem se dando por meio da nossa participação em grupos de estudos do qual fazem parte pesquisadores interessados na temática, objeto do nosso estudo. Outra orientação que importa assinalar diz respeito ao fato de nossa pesquisa acolher bolsistas de iniciação à docência. Assim, um dos objetivos do projeto contempla o aprimoramento da formação de licenciandos, com vistas a potencializar a pesquisa filosófica sobre o ensino da filosofia na educação básica e, com isso, qualificar o curso de licenciatura em filosofia da Universidade Federal de Goiás.' 
Finalmente, mais algumas palavras quanto ao caráter experimental da nossa pesquisa. Tal como pensamos, os experimentos podem ou não dar certo. Vivemos em um tempo de experimentação permanente, alimentada pelo mercado, em nome do desenvolvimento e do progresso. Toda pesquisa precisa ter finalidade, que é buscar inovações. Não é isso que buscamos. Estamos interessados em atividades de criação e de experimentação no campo das práticas pedagógicas e é dessa perspectiva que podemos começar o desenho de uma educação para a resistência que encoraje a reflexão sobre os desafios propostos pelas filosofias da diferença, identificando novos papéis, concepções e perspectivas para a Educação.

Nossa pretensão é traçar novos horizontes para a filosofia em suas relações com a educação e a pedagogia, empreendendo um esforço para instituir nesse campo práticas desviantes das práticas de assujeitamento, afastadas, portanto, dos procedimentos modernos de normalização. Assim, estamos cientes dos riscos que corremos, com propostas como essa, de produzir experiências "desviantes" de exercícios de liberdade no campo da educação, por meio de práticas educativas que tomam como princípio ético-político, no lugar das práticas de normalização, o cuidado de si e a estetização da existência.

\section{A EDUCAÇÃO ENTRE A BIOPOLÍTICA E A RESISTÊNCIA}

O conceito de biopolítica está atravessado por uma ambivalência de fundo, por uma incerteza, uma inquietação e está exposto "a uma pressão hermenêutica crescente que parece fazer dele não só instrumento como também objeto de um áspero confronto, filosófico e político, sobre a configuração e o destino do nosso tempo" (ESPOSITO, 2010, p. 30). Biopolítica diz respeito a uma colonização, uma pura objetivação da vida por parte do poder, ou à expansão de potencialidades capazes de reinventar os corpos e a realidade do social, o corpo biopolítico coletivo, em seu misto de inteligência, conhecimento, afeto e desejo? E a vida? Ela é primeiramente objeto de individualização por parte do biopoder ou instância de problematização ética e construção de subjetividades não normativas? Afinal, biopoder e biopolítica referem-se a "um poder sobre a vida ou um poder da vida"? (ESPOSITO, 2010).

As noções de poder e vida ocupam um lugar central nas análises de Foucault acerca das mutações epistemológicas e políticas por meio das quais emergiu um dos fenômenos fundamentais de nossa modernidade política, a saber, a entrada do corpo e da vida nos cálculos do poder, à maneira pela qual, 
a partir do século XVIII, se buscou racionalizar os problemas colocados para a prática governamental pelos fenômenos próprios de um conjunto de viventes enquanto população. Pela primeira vez na história, categorias científicas, tais como espécie e população, mais do que as jurídicas tornaram-se objeto de atenção política sob uma forma mais consistente e precisa. O poder, agora, tende a governar os indivíduos na base da incitação, do controle, da vigilância, visando à otimização das forças que ele submete. Gerir a vida, mais do que decretar a morte. E quando exige a morte, é em nome da defesa da vida que ele se encarregou de administrar. Curiosamente, é quando mais se fala em defesa da vida que ocorrem as guerras mais abomináveis e genocidas. Foucault explica:

jamais as guerras foram tão sangrentas como a partir do século XIX e nunca, guardadas as proporções, os regimes havia, até então, praticado tais holocaustos em suas próprias populações. Mas esse formidável poder de morte (...) apresenta-se agora como um complemento de um poder que se exerce, positivamente, sobre a vida, que empreende sua gestão, sua majoração, sua multiplicação, o exercício, sobre ela, de controles precisos e regulações de conjunto. As guerras já não se travam em nome do soberano a ser defendido; trava-se em nome da existência de todos; populações inteiras são levadas à destruição mútua em nome da necessidade de viver. Os massacres se tornaram vitais. Foi como gestores da vida e da sobrevivência dos corpos e da raça que tantos regimes puderam travar tantas guerras, causando a morte de tantos homens (1988, p. 129).

É nesse sentido que os genocídios modernos não devem ser vistos como uma volta ao velho direito "soberano" de matar, mas como uma forma articulada ao poder que se situa e se exerce ao nível da vida, da espécie, da raça, em suma, dos fenômenos maciços de população. Ao ampliar o espectro de sua análise, Foucault insere, também, a biopolítica no interior de uma relação problemática entre vida e história. Pela primeira vez a vida entrou na história, isto é, fenômenos da espécie humana entraram na ordem do saber e do poder, no campo das técnicas políticas. Ora, a vida sempre fez pressão sobre a história, sobretudo através das epidemias e da fome, mas só quando estas começaram a ser relativamente controladas é que a vida começou, de fato, a ser objeto de saber, e a espécie vivente, tomada como uma força que se pode modificar e repartir tornou-se o alvo do poder.

Se a irrupção da vida na história, por meio das epidemias e da fome, pode ser chamada de bio-história, agora se trata de biopolítica - a vida e seus mecanismos entram nos cálculos explícitos do poder e saber, enquanto 
estes se tornam agentes de transformação da vida. A espécie torna-se, assim, a grande variável nas próprias estratégias políticas, pois quando o biológico passa a incidir sobre o político, o poder já não se exerce sobre sujeitos de direito, cujo limite é a morte, mas sobre seres vivos, de cuja vida ele deve encarregar-se. Eis aí a face sombria da modernidade que, ao atribuir à vida um valor político supremo, ao mesmo tempo decidiu de forma resoluta sobre o valor e o desvalor da vida enquanto tal. Quando a vida torna-se o valor político supremo, coloca-se aí também o problema de seu desvalor. Estamos, como se vê, diante de um paradoxo. Na verdade, tudo se desenrola como se nesta decisão estivesse em jogo a consistência última de um poder supremo, um poder soberano. Esclarece-se, assim, a afirmação feita por Agamben segundo a qual "na biopolítica moderna, soberano é aquele que decide sobre o valor ou sobre o desvalor da vida enquanto tal" (2002, p. 149).

É, pois, a identificação desse paradoxo que nos leva a explorar problemas e possibilidades que emergem dessa vacilação de fundo presente nesse cenário em que a vida, se está submetida aos aparatos biopolíticos, ao mesmo tempo ela é o lugar a partir do qual podem proliferar devires minoritários ou o campo ético das subjetivações. "Devir-minoritário", como mostra Deleuze (1997, p. 89), "é um caso político, e apela a todo um trabalho de potência, uma micropolítica ativa". No pensamento tardio de Foucault, o campo ético das subjetivações corresponde ao problema das "técnicas de si", isto é, da relação do sujeito consigo mesmo, com os outros e com a verdade. Assim, em seu trabalho genealógico interessa a Foucault explorar as condições de possibilidade de uma vida como obra de arte, inseparável, pois, de uma estética da existência.

Embora Foucault tenha designado de biopolítica a entrada do corpo e da vida nos cálculos do poder, ele próprio intuíra que aquilo mesmo que o poder investia - a vida - era precisamente o que doravante ancoraria a resistência a ele, numa reviravolta inevitável. Não reconhecer, portanto, o lugar da resistência equivaleria a desconhecer o caráter estritamente relacional dos modos de relações de poder. A todo tipo de poder corresponde um tipo de resistência e de luta. "Lá onde há poder, há resistência e, no entanto (ou melhor, por isso mesmo) esta nunca se encontra em posição de exterioridade em relação ao poder" (FOUCAULT, 1988, p. 91). As resistências são plurais e não podem existir a não ser no campo estratégico das relações de poder. Foucault insiste, portanto, em três pontos: a resistência é coextensiva ao poder que ela enfrenta, não havendo, pois, uma anterioridade da resistência; há uma similaridade de características entre o poder e a resistência: inventividade, 
mobilidade, produtividade, organicidade e, ela se distribui estrategicamente, tal como o poder; o par poder e resistência podem, por fim, fundar novas relações de poder, assim como, inversamente, a invenção de novas formas de resistência também pode emergir desse caráter relacional a partir do qual Foucault empreende uma analítica do poder.

No caso de transformação dos mecanismos disciplinares instituídos na sociedade moderna e dos dispositivos de controle que crivam as nossas sociedades de controle contemporâneas, certamente, será preciso atuar estrategicamente dentro da rede do poder. Isso significa que, no lugar de pensar em transformações que possam vir de cima para baixo, ou seja, do regime de governo ou do aparelho de Estado, seria mais produtivo pensar em formas de atuação e de constituição de redes dentro da rede do próprio poder. Assim como os poderes, "as lutas, para serem eficazes, precisam ser plurais, heterogêneas, móveis, provisórias, pontuais" (MUCHAIL, 2004, p. 243).

Eis o pano de fundo, a partir do qual seria possível pensar o devireducação e suas virtuais relações com a biopolítica. A questão é: se o capitalismo precisou investir nos corpos para torná-los objetos de controle político, manipulação cultural e instrumentalização econômica tratar-se-ia, então, de nos opor a esses investimentos que constituem poderosos meios de reprodução dos mecanismos de dominação e de exclusão e conduzem à adoção de uma relação com o outro que é de indiferença. Tratar-se-ia, em suma, de buscar nos próprios homens, o conjunto das forças que resistem aos mecanismos de dominação e de exclusão no nosso tempo.

Assumindo questões deste tipo, acolhemos a sugestão de Foucault, para quem o sentido ético da urgente tarefa de constituir uma ontologia histórica da atualidade, passa, também, pela indagação do "que estamos ajudando a fazer de nós mesmos.". Isto inclui um cuidado permanente sobre si mesmo, sobre um si mesmo que se sabe consciente e inconscientemente impregnado de condições históricas a serem transformadas. É por isso que também nós nos incluímos no campo das problematizações deste ensaio.

RESISTIR AO SEQUESTRO DA VIDA PELO PODER OU “É INÚTIL REVOLTAR-SE"?

Estamos acostumados a encarar a resistência, historicamente falando, mais como uma reação do que propriamente uma ação, mais como uma defesa do que como uma ofensiva, mais como oposição do que como revolução. Contudo, se seguimos aqui o percurso empreendido por Peter Pál Perbart (2003), há de se perguntar: como encarar a resistência hoje? A lógica da 
resistência permanece o que ela foi no alvorecer da modernidade - oposição direta das forças em jogo - ou existem outros traçados de conflitualidade sugerindo que a função da própria negatividade, na política, na educação e na cultura, precise ser revista? Por outro lado, como propõe Cornelius Castoriadis (2001), como encarar o "esgotamento ideológico" que domina a paisagem político-educacional do nosso tempo, que vem acompanhado de uma "disposição geral" que é de resignação ou de "conformismo generalizado", de "inibição para agir"? Com efeito, os âmbitos político e educacional estão marcados pelo esgotamento de uma proposta significativa de transformação social, enquanto que, no âmbito cultural, há uma saturação de marketing e consumismo. Mas essas misérias do nosso tempo devem se reduzir a esse desenho austero?

Aparentemente, não há condições de possibilidade de resistência à captura da vida pelos biopoderes. Como bem o observou Pelbart, em um texto sugestivamente intitulado de Vida nua, vida besta, uma vida, "ao reduzir a existência ao seu mínimo biológico, o biopoder contemporâneo nos transforma em meros sobreviventes". 3 Para Pelbart, esses poderes são as ciências, o capital, o mercado, o Estado, a mídia.

Se antes ainda imaginávamos ter espaços preservados da ingerência direta dos poderes (o corpo, o inconsciente, a subjetividade) e tínhamos a ilusão de preservar em relação a eles alguma autonomia, hoje nossa vida parece integralmente subsumida a tais mecanismos de modulação da existência. (PELBART, 2007, p.1).

Os biopoderes não visam barrar a vida, antes, tendem a encarregar-se dela, intensificá-la, torná-la produtiva, otimizá-la, digamos assim, correndo todos os riscos de simplificação. O fato é que não há "nenhuma exterioridade que se sustente, nenhum contrapoder à vista, a menos que se reproduza pelo avesso aquilo de que se quer se libertar." (REVEL, 2006, p. 58). Trata-se, então, de perscrutar se as hipóteses que nos orientam são defensáveis, já que nosso propósito aqui é precisamente, de um lado, invocar a potência da vida para captar a resistência possível ao seu sequestro pelo poder e, de outro, a aposta de que a educação e, mais especificamente, a sala de aula, é o lugar próprio à constituição de sujeitos ativos.

Para Foucault, "insurgir-se é um fato" e é por isso mesmo que "a subjetividade (não a dos grandes homens, mas a de qualquer um) se introduz na história e Ihe dá seu alento" (2004a, p. 78). Exemplifiquemos com o delinquente que arrisca sua vida contra castigos abusivos; com o louco que 
não suporta mais estar preso e decaído; com um povo que recusa o regime que o oprime. No entanto, isso não torna

[o delinquente] inocente, não cura o outro [o louco] e não garante ao terceiro [o povo] os dias prometidos. Aliás, ninguém é obrigado a ser solidário a eles. Ninguém é obrigado a achar que aquelas vozes confusas cantam melhor do que as outras e falam da essência do verdadeiro. O que importa é que essas vozes existam. Basta que elas existam e que tenham contra elas tudo o que se obstina em fazê-las calar, para que faça sentido escutá-las e buscar o que elas querem dizer (FOUCAULT, 2004a, p. 80). ${ }^{4}$

Se não podemos mais nos contentar em dizer que as velhas lutas não valem mais, faz-se necessário perguntar que poderes enfrentar e quais são as condições de possibilidade de resistência hoje. Não seria o caso evocar novas modalidades de resistência, não como antes, proveniente de uma classe, de um partido, de um sindicato, de um grupo, de uma minoria, mas proveniente de uma singularidade qualquer, do qualquer um? Uma singularidade qualquer que

recusa o poder constituído sem constituir uma réplica espelhada desse mesmo poder, na figura partidária ou ideológica. A singularidade qualquer, que não reivindica uma identidade, que não faz valer um liame social, que constitui uma multiplicidade inconstante. Singularidades que declinam toda identidade e toda condição de pertinência, mas manifestam seu ser comum - é a condição, dizia Agamben há vários anos, de toda política futura (PELBART, 2003, p. 140-1).

Ou, ainda, nos termos em que Deleuze propõe:

e será, acima de tudo, que não estamos assistindo, participando da 'produção de uma nova subjetividade'? As mutações do capitalismo não encontram um 'adversário' inesperado na lenta emergência de um novo Si como foco de resistência? Cada vez que há uma mutação social, não há um movimento de reconversão subjetiva, com suas ambiguidades, mas também seus potenciais? Essas questões podem ser consideradas como mais importantes, inclusive para o direito puro, do que a referência a direitos humanos universais $(1988$, p. 123).

A perspectiva de Deleuze aponta, assim, para a necessidade de reencontrar a capacidade embutida na própria vida, de fazer variar suas formas. Tratar-se-ia, então, "de reencontrar aquela uma vida, ${ }^{5}$ tanto em sua "beatitude' quanto na capacidade nela embutida de fazer variar suas formas" (PELBART, 2003, p. 51). Talvez, assim, pudéssemos retornar à biopolítica e às 
perguntas formuladas no nosso ponto de partida, especialmente àquela que faz-nos pensar em uma biopolítica afirmativa, ao poder da vida, invocando o sentido originário do termo bios e, em particular aristotélico, como "vida qualificada". Uma vida, não mais subtraída da sua potência de variação; uma vida, desprendida dos dispositivos de poder e de saber que têm em conta a possibilidade de controlá-la e modificá-la; uma vida, no sentido afirmativo, ali onde se reconhece, na dimensão intensiva, ontológica e constitutiva, a âncora da resistência, a potência de variação das formas de vida. Uma vida, lugar de invenção de novas formas de relação consigo e com os outros, "lugar de criação de uma nova subjetividade que doar-se-ia como um momento de desassujeitamento" (REVEL, 2006, p. 58). O acolhimento das variações e formas de vida coloca, no entanto, a exigência do afastamento de uma acepção predominantemente biológica, incluindo no conceito de vida, a sinergia coletiva, a cooperação social e subjetiva no contexto de produção material e imaterial contemporânea, o afeto, o desejo, enfim, o "poder de afetar e ser afetado" (PELBART, 2003, p. 25).

Foucault lembra que as grandes lutas que põem em questão o sistema geral de poder, são lutas que não se fazem propriamente em nome de direitos, mas o que é reivindicado e serve de objetivo é a vida, entendida

como as necessidades fundamentais, a essência concreta do homem, a realização de suas virtualidades, a plenitude do possível. Pouco importa que se trate ou não de utopia; temos aí um processo bem real de luta; a vida como objeto político foi de algum modo tomada ao pé da letra e voltada contra o sistema que tentava controlá-la. Foi a vida, muito mais do que o direito, que se tornou o objeto das lutas políticas, ainda que estas últimas se formulem através de afirmações de direito. O 'direito' à vida, ao corpo, à saúde, à felicidade, à satisfação das necessidades, o 'direito', acima de todas as opressões ou alienações, de encontrar o que se é e tudo o que se pode ser (FOUCAULT, 1988, p. 136).

Eis aí colocada as premissas em torno das quais ganha toda a relevância a argumentação de Gabriel Giorgi e Fermín Rodríguez (2007). Para esses autores é a partir da própria vida nua ${ }^{6}$ que outras formas de vida podem ser extraídas. Assim, poder-se-ia estabelecer uma nova relação política entre "vida humana" e "vida", a partir dos modos pelos quais o meramente biológico - o ser vivente do humano - se constituiria em instância de reinvenção e de experimentação, de subjetivação e criação de novas formas de vida, mais além e contra as tecnologias de reprodução de uma humanidade normativa e normalizada. 
Para Foucault, existem três formas de lutas possíveis:

contra as formas de dominação (étnica, social e religiosa); contra as formas de exploração que separam os indivíduos daquilo que eles produzem; ou contra aquilo que liga o indivíduo a si mesmo e o submete, deste modo, aos outros (lutas contra a sujeição, contra as formas de subjetivação e submissão) (1995, p. 235).

Nos nossos dias, porém, as lutas contra as formas de subjetivação são as mais importantes, o que não significa que os outros dois tipos de lutas não sejam. Nesse sentido, Foucault busca com a formulação - o "cuidado de si" nome dado ao processo de autoconstituição de nós mesmos, como "o ponto de resistência prioritário e útil contra o poder político"e, como consequência, concebe seu projeto filosófico e político como um fomento de novas formas de subjetividade. Se quisermos, então, nos contrapor ao mal-estar produzido pela sociedade normalizadora e ao controle das subjetividades, talvez devêssemos levar mais a sério a advertência de Foucault: "o objetivo hoje em dia [talvez] não seja descobrir o que somos, mas recusar o que somos" (FOUCAULT, 1995, p. 239). É esse uso intransitivo da liberdade que escolhemos sublinhar aqui, pois as lutas de resistência, "no caso particular da individuação, são lutas pela autonomia e emancipação. Exigem, para tal, um trabalho contínuo e sem descanso de afrontamento dos processos de autonomização contra as técnicas de individuação e normalização" (CASTELO BRANCO, 2005, p. 182).

E a filosofia, como sugere Foucault (1995), talvez tenha muito a contribuir, pois o seu duplo papel, de prevenir, de um lado, a razão de ultrapassar os limites daquilo que é dado na experiência, por outro, ao mesmo tempo - isto é, desde o desenvolvimento do Estado moderno e da gestão biopolítica da sociedade -, o papel da filosofia é também vigiar os excessivos poderes da racionalidade política. Enfrentar esse duplo desafio, porém, supõe a ocupação com um trabalho do pensamento para"tentar saber de que maneira e até onde seria possível pensar diferentemente em vez de legitimar o que já se sabe" (FOUCAULT, 1984, p. 13). É com esse propósito que Foucault retorna à Antiguidade greco-romana para reencontrar no"corpo vivo da filosofia", formas de subjetividade inteiramente afastadas da normalização de nossas sociedades atuais. Do mesmo modo, se é possível determinar como Foucault se interessa pela política e pela ética, suas próprias palavras podem esclarecer o que de fato importa aqui:

É possível suspeitar que haja uma certa impossibilidade de constituir hoje uma ética do eu, quando talvez seja esta uma tarefa urgente, fundamental, 
politicamente indispensável, se for verdade que, afinal, não há outro ponto, primeiro e último, de resistência ao poder político senão na relação de si para consigo" (FOUCAULT, 2004, p. 306).

Abramos aqui um parêntese para frisar que os deslocamentos aqui propostos no campo conceitual, se nos permite pensar a biopolítica de outra perspectiva, é porque as lutas de resistência, o que elas visam - como mostra Foucault -, é a defesa da liberdade. O último Foucault está interessado, de fato, "na maneira com a qual o sujeito se constitui de uma maneira ativa, através das práticas de si"(2004, p. 276), isto é, das práticas de liberdade. Foucault é muito claro: "só é possível haver relações de poder quando os sujeitos forem livres" (2003, p. 276). No último Foucault, como se vê,"restaura-se o lugar e o papel dos indivíduos, dos indivíduos éticos, sensíveis e racionais no quadro das lutas políticas" (CASTELO BRANCO, 2005, p. 178). É dentro desse quadro que vislumbramos as condições de possibilidade da resistência no campo da educação.

\section{À GUISA DE CONCLUSÃO - POR UMA "EDUCAÇÃO MENOR"}

Uma das características das literaturas menores "é que nelas tudo é político" (DELEUZE, 1977, p. 26). Igualmente, poder-se-ia dizer que uma das características da educação é também esta, a de guardar uma estreita relação com o político. A literatura "produz uma solidariedade ativa, apesar do ceticismo" (DELEUZE, 1977, p. 27). A educação também não poderia produzir essa solidariedade reivindicada por Deleuze? "O escritor está à margem ou afastado de sua frágil comunidade [e] essa situação o coloca ainda mais em condição de exprimir uma outra comunidade potencial, de forjar os meios de uma outra consciência e de uma outra sensibilidade" (DELEUZE, 1977, p. 27). Nós, professores, comprometidos com uma educação, cujo primado seja o princípio ético-político da estilização da existência, não nos caberia examinar com mais acuidade a proposta de constituição de uma "educação menor" em termos semelhantes ao que Deleuze propõe na obra Kafka - por uma literatura menor? Nessa direção,

para além da educação maior contida nas ações governamentais de todas as esferas, contida nas políticas e planos de educação, assim como nos chamados projetos pedagógicos, que está sempre marcada por uma heteronomia e por práticas de assujeitamento, importa-nos essa prática educativa que cada professor realiza na solidão de sua sala de aula, na reciprocidade de sua relação com os estudantes. Se as instituições escolares modernas foram construídas como espaços de subjetivação pela sujeição, é nas práticas 
desviantes daqueles que escolhem correr os riscos de produzir experiências de liberdade no cotidiano da escola, inventando uma prática educativa que toma como princípio ético a estetização da existência, que reside a possibilidade de resistência e criação (GALLO, 2006, p. 188).

A educação depende, assim, dos gestos que a fazem. É dessa perspectiva que, tal como pensamos, as práticas educativas buscam (ou deveriam buscar) libertar a vida daquilo que a aprisiona. Retornemos a Foucault. Se os bipoderes se debruçam sobre a vida e não sobre sujeitos de direito, então, cabe à própria vida resistir. Esta resistência da vida pode denominar-se biopolítica. Uma educação para resistência, por sua vez, tal como postulamos aqui, está interessada em intensificar a relação entre pensamento, corpo e vida. Eis as condições de possibilidade de uma educação e de uma atividade filosófica que pretendam corporificar atos de resistência. Resistir: este é, sem dúvida, o nosso "dever". Dever que expressamos aqui sob a forma de um imperativo tomado de empréstimo a Karl Jaspers. Invocamo-lo de memória: "é importante estar plenamente presente". Isso significa recuperar o interesse pela história, pela educação, pela política, pela vida e lançar-se na ação. Afinal, nas instituições educacionais, não estamos nós governando outros e ensinando-lhes a governar-se?

\section{EDUCATION UNDER THE SIGN OF BIOPOLITICS: FROM RESISTANCE TO FORMS OF CONTROL TO THE SELF-CONSTITUTION OF OURSELVES}

ABSTRACT: The proposal of this essay is to reflect on the becoming of education and its potential relations with biopolitics. We start from the hypothesis that the technologies of knowledge-power and control and normalization devices cannot work without a teaching vector. Therefore, if biopolitics invests in bodies to make them objects of political control, cultural manipulation, and economic exploitation, our task is to oppose these attacks and invoke the power of resistance lodged in these individuals. For Foucault, the ethical sense of the urgent task of building a historical ontology of actuality also involves inquiring what we are making of ourselves. If our own formation of self involves the task of educating against and beyond our own time, then we should take seriously the warning of Nietzsche with which Foucault certainly agrees: educators must begin by educating themselves. "And it is for them that I am writing".

KEYWORDS: Biopolitics. Education. Resistance. Formation of self. 
LA EDUCACIÓN BAJO EL SIGNO DE LA BIOPOLÍTICA: DE LA RESISTENCIA A LAS FORMAS DE CONTROL Y A NUESTRA AUTOCONSTITUCIÓN

RESUMEN: La propuesta del ensayo es pensar el devenir de la educación y sus relaciones virtuales con la biopolítica. Partimos de una hipótesis según la cual las tecnologías de saber-poder y los dispositivos de control y normalización no pueden funcionar sin un vector pedagógico. Consecuentemente, si la biopolítica invierte en los cuerpos para convertirlos en objetos de control político, manipulación cultural e instrumentalización económica, trataríamos de oponernos a esas inversiones e invocar a las fuerzas de resistencia residentes en los propios individuos. Según Foucault, el sentido ético de la urgente tarea de constituir una ontología histórica de la actualidad pasa, también, por la investigación que estamos haciendo sobre nosotros mismos. Pues, si en la formación de uno mismo está implícita la tarea de educarse contra y hacia más allá de su propio tiempo, tomemos en serio el alerta de Nietzsche con el cual Foucault, ciertamente, concordaría: los educadores deben comenzar por educarse a sí mismos. "Y es a ellos a quienes escribo".

Palabras claves: Biopolítica. Educación. Resistencia. Formación de sí mismo.

\section{NOTAS}

1) A autora participa do Kalós - Núcleo de Estudos e Pesquisas sobre o Ensino da Filosofia e do Grupo de Estudos em Biopolítica, ambos vinculados à Faculdade de Filosofia da UFG. Além da participação nesses grupos, coordena desde 2010 o projeto de Filosofia vinculado ao Programa Institucional de Bolsa de Iniciação à Docência - PIBID, financiado pela Capes. O projeto conta com a participação de 12 (doze) estudantes do curso de Licenciatura em Filosofia, na condição de bolsistas de iniciação à docência.

2) "Que estamos ajudando a fazer de nós mesmos?". Essa pergunta abre a apresentação do livro que reúne os textos produzidos para o Colóquio Foucault-Deleuze, realizado na Unicamp, em 2000 e publicados no livro Imagens de Foucault e Deleuze - ressonâncias nietzschianas, organizado por Margareth Rago, Luiz B. Lacerda Orlandi e Alfredo Veiga-Neto. A exemplo dos organizadores deste colóquio, nosso interesse é sondar, através desta pergunta "a nossa potência de variar no próprio meio que nos constitui" (2005, p. 9).

3) Disponível em: <www.jfreirecosta.com>. Acesso em: 12 nov. 2006.

4) Contra o pensamento estratégico, Foucault se insurge para circunscrever sua moral teórica antiestratégica: "ser respeitoso quando uma singularidade se insurge, intransigente quando o poder infringe o universal. Escolha simples, obra penosa, pois é preciso ao mesmo tempo espreitar, por baixo da história, o que a rompe e a agita, e vigiar um pouco por trás da política o que deve incondicionalmente limitá-la" (2004a, p. 81). 
5) Apropriamo-nos aqui do sentido atribuído por Deleuze ao que ele próprio denominou uma vida. Uma vida se afirma como imanência e virtualidade através e mais além das distribuições hierárquicas que inscrevem e produzem politicamente o humano. “Pode-se dizer da pura imanência que ela é uma vida, e nada diferente disso [...] Uma vida é [...] a imanência absoluta: ela é potência completa, beatitude completa [...].Uma vida está em toda parte, em todos os momentos que este ou aquele sujeito vivo atravessa [...]; vida imanente que transporta os acontecimentos ou singularidades que não fazem mais do que se atualizar nos sujeitos e nos objetos [...].Uma vida não contém nada mais que virtuais. Ela é feita de virtualidades, acontecimentos, singularidades. Aquilo que chamamos de virtual não é algo ao qual falte realidade, mas que se envolve em um processo de atualização ao seguir o plano que lhe dá sua realidade própria" (DELEUZE apud GIORGI e RODRÍGUEZ, 2007, p. 35-40; a tradução é nossa).

6) Segundo Giorgio Agamben, não a simples vida natural, mas a vida exposta à morte (a vida nua ou a vida sacra) é o elemento político originário. Por isso, a denominação Homo sacer, tal como aparece conjugada à expressão "vida nua", remete a uma obscura figura jurídica do direito romano arcaico, aplicada ao homem que se encontrava simultaneamente fora da legislação humana e da legislação divina, que retinha em si a ambiguidade do sagrado, da sacratio, sendo simultaneamente sublime e monstruoso. O homo sacer é a figura por meio da qual a vida humana se inclui na ordem jurídica unicamente sob a forma de sua exclusão, pois constitui a figura jurídica daquele que pode ser morto por qualquer um, desde que tal morte não seja o resultado de um ritual ou processo jurídico. A expressão sacer indica uma "vida absolutamente exposta a que se lhe dê a morte, objeto de uma violência que excede tanto a esfera do direito como a do sacrifício" (AGAMBEN, 2002, p. 112).

\section{REFERÊNCIAS}

AGAMBEN, G. Homo Sacer - o poder soberano e a vida nua, v. I. Tradução de Henrique Burigo. Belo Horizonte: Editora UFMG, 2002.

CASTELO BRANCO, G. As lutas pela autonomia em Michel Foucault. In: RAGO, Margareth; ORLANDI, Luiz B. Lacerda; VEIGA-NETO, Alfredo (Org.). Imagens de Foucault e Deleuze - ressonâncias nietzschianas. 2. ed. Rio de Janeiro: DP\&A, 2005. p. 175-184.

CASTORIADIS, C. Post-scriptum sobre a Insignificância - entrevista a Daniel Mermet. Tradução de Salma Tannus Muchail e Maria Lúcia Rodrigues. São Paulo:Veras Editora, 2001.

DELEUZE, G. "La Inmanencia: una vida...." In: GIORGI, Gabriel; RODRÍGUEZ, Fermín (Org.). Ensayos sobre Biopolítica: excesos de vida. Buenos Aires: Paidós, 2007. p. 35-40.

. Mil Platôs - capitalismo e esquizofrenia, v. IV. Tradução de Suely Rolnik. São Paulo: Editora 34, 1997.

. Conversações (1972-1990). Tradução de Peter Pál Pelbart. Rio de Janeiro: Editora 34, 1992. 
. Foucault. Tradução de Claudia Sant'Anna Martins. São Paulo: Brasiliense, 1988.

. Kafka - por uma literatura menor. Tradução de Júlio Castañon Guimarães. Rio de Janeiro: Imago Editora, 1977.

ESPOSITO, R. Bios - biopolítica e filosofia. Lisboa: Edições 70, 2010.

FOUCAULT, M. A Hermenêutica do Sujeito. Tradução de Márcio Alves da Fonseca e Salma Tannus Muchail. São Paulo: Martins Fontes, 2004.

.Ética, Sexualidade, Política (Ditos \& Escritos V). Tradução de Elisa Monteiro e Inês Autran Dourado Barbosa. Rio de Janeiro: Forense Universitária, 2004a.

. Estratégia, Poder-saber (Ditos \& Escritos IV). Tradução de Vera Lucia Avellar Ribeiro. Rio de Janeiro: Forense Universitária, 2003.

. O sujeito e o poder. In: RABINOW, Paul; DREYFUS, Hubert. Michel Foucault: uma trajetória filosófica - para além do estruturalismo e da hermenêutica. Tradução de Vera Portocarrero. Rio de Janeiro: Forense Universitária, 1995. p. 231-249.

. História da sexualidade, I - A vontade de saber. Tradução de Maria Thereza da Costa Albuquerque e J. A. Guilhon Albuquerque. 9. ed. Rio de Janeiro: Edições Graal, 1988.

. História da sexualidade, II - O uso dos prazeres. Tradução de Maria Thereza da Costa Albuquerque. 5. ed. Rio de Janeiro: Edições Graal, 1984.

GALLO, S. Cuidar de si e cuidar do outro: implicações éticas para a educação dos últimos escritos de Foucault. In: GONDRA, José; KOHAN, Walter (Org.). Foucault 80 Anos. Belo Horizonte: Autêntica, 2006. p. 177-189.

GIORGI, G.; RODRÍGUEZ, F. (Org.). Prólogo. In: .Ensayos sobre Biopolítica - excesos de vida. Buenos Aires: Paidós, 2007. p. 9-34.

MUCHAIL, S.T. Democracia como prática: algumas reflexões a partir de M. Foucault e C. Castoriadis. In: CALOMENI, Tereza Cristina B. (Org.). Michel Foucault - entre o murmúrio e a palavra. Campos, RJ: Editora Faculdade de Direito de Campos, 2004. p. 239-245.

PELBART, P. P. Vida Capital - ensaios de biopolítica. São Paulo: Iluminuras, 2003.

. Vida Nua, Vida Besta, uma Vida. Trópico, p. 1-5, 2007. Disponível em: <http://p. php.uol.com.br/tropico/html/textos/2792,1.shl>. Acesso em: 10 ago.2014.

PORTOCARRERO, V. Os limites da vida - da biopolítica aos cuidados de si. In: ALBUQUERQUE JÚNIOR, D. M.; VEIGA-NETO, A.; SOUZA FILHO, A. (Org.). Cartografias de Foucault. Belo Horizonte: Autêntica Editora, 2008. p. 419-430. (Coleção Estudos Foucaultianos).

RAGO, M.; ORLANDI, L. B. L.; VEIGA-NETO, A. (Org.). Imagens de Foucault e Deleuze ressonâncias nietzschianas. 2. ed. Rio de Janeiro: DP\&A, 2005.

REVEL, J. Nas origens do biopolítico: de Vigiar e Punir ao pensamento da atualidade. In: GONDRA, J.; KOHAN, W. (Org.). Foucault 80 Anos. Belo Horizonte: Autêntica, 2006. p. 51-62. 
CARMelita BRITO de Freitas Felíclo é mestre em Filosofia pela Universidade Federal de Goiás. Atualmente, é professora na Faculdade de Filosofia da UFG. Tem experiência nas áreas de Filosofia Política e Formação de Professores, e seus interesses de pesquisa estão relacionados aos seguintes autores: Hannah Arendt, Michel Foucault e Gilles Deleuze. E-mail:carmelaf@terra.com.br 